\title{
The Challenges of Integrating Women in Leadership Positions in the Technology Industry
}

Dionisia Richilene Vaz Cidre ${ }^{a}$, Lisa Weidman ${ }^{b}$, Bachelor of Commerce Honours in Management, 13022328, 'bupervisor

The technology industry seems lacking as in the sector women are more underrepresented in leadership positions; not only that but they are also underpaid, often passed for promotions and faced with everyday sexual harassment (McDonald and Charlesworth, 2015; Vivek, 2016; Waldring, Crul and Ghorashi, 2015). This paper aims to explore the challenges of integrating women in leadership positions in the technology industry. Therefore, to reach the aim of this study, a qualitative research method was used, and an in-depth interview approach was employed to explore the challenges of integrating women in leadership positions in the technology industry. The findings revealed that the main challenges faced by women in the advancement of their careers in the technology industry involve gender discrimination, the working environment and sexual harassment.

Key words: Leadership, Technology industry, challenges, discrimination.

\section{INTRODUCTION}

The research topic of this paper is described in this chapter. The definition of the topic and purpose of the study and its importance are also explained. Further, in this chapter, the problem discussion that necessitates the need for doing this research paper along with the clear and precise objective of the study, is described.

Compared to several decades' past, women have made leaps in terms of advancing toward senior executive positions formerly monopolized by men. However, career advancement opportunities for women still lag considerably as a result of social barriers and challenges to ascend in leadership positions, especially in the technology industry (Glass, 2016). This phenomenon has been referred to as the "glass ceiling," a term originally used in 1986 by a Wall Street journalist to connote the status of women in the corporate world. The term was 
coined as a description of the complex barriers that block women's opportunities to break through the top levels in the organization. Women who work in a male-dominated industry, such as the technology industry, tend to face more challenges compared to those who work in a gender-balanced and female-dominated industry. Therefore, this study aims to explore the challenges of integrating women in leadership positions in the technology industry, and how these challenges affect their performance and career-success (Ashcraft, 2016).

\subsection{Rationale}

According to Ashcraft (2016), it is commonly acknowledged that women are vastly underrepresented at the highest level of businesses. South Africa seems to be encouraged to increase the percentage of women in senior management teams, but the average is still rising slowly in male-dominant industries such as the technology industry, where women fall dramatically behind men in many aspects, and tend to face diverse challenges to enhance their career success (Bac, 2018; Chizema, Kamuriwo, and Shinozawa, 2015). Many studies have reported on the various barriers that women encounter during professional advancement but have not delved into the why of this issue, and without speaking to the specific issues that women face in the male-dominated workplace, women may struggle and falter in their climbs. Until now, technology workplaces carry the same biases that have existed traditionally, namely that women are not suitable for technology careers or they will not be able to bring anything to the company if they are in a tech-orientated role. Despite the discussions about diversity and inclusion in organizations, women in leadership roles are still in the minority (Vivek, 2016).

This topic was chosen because there is a tremendous need to explore the challenges of integrating women in leadership positions and to understand the reason why, as it remains unclear (Correll, 2016). Women still have fewer opportunities than their male counterparts to showcase their full potential and must work harder and prove themselves repeatedly, as they work their way up to senior positions (Holtzblatt, 2018). This qualitative research aims to provide an overview of the main challenges faced by women in leadership positions in the technology industry. This study will enable companies to understand how these challenges affect women's careers and how to overcome them, to increase opportunities for female executives in the technology industry and to ensure inclusivity. Furthermore, this study will provide an in-depth understanding of the reasons why women are still facing those challenges. Overall, this study will provide data from researchers and practitioners in various fields of study with foundations and strategic frameworks to be used for more reflective teaching, research, and practice around the topic of women and leadership.

\subsection{Problem statement}

The technology industry is known as a male-dominant environment, and the lack of women in leadership positions is a recurring issue. According to previous studies, women tend to 
face different barriers and challenges to advance their careers in the technology industry (Aydalot, and Keeble, 2018). There is an extreme need to explore the challenges of integrating women in leadership positions in the technology industry; for this reason, several methods should be employed to combat this problem. An action must be taken; technology companies should adopt strategies to explore and analyse the challenges that are interfering in women's prospects in the technology industry.

\subsection{Research purpose and objectives}

The main purpose of this study is to explore the challenges of integrating women in leadership positions in the technology industry. By conducting qualitative research to provide an overall summary of the key barriers to women's participation in technology and promising practices for addressing these barriers, it will serve as a reference and resource for educators, policymakers, and others who wish to raise awareness and advocate for change.

There is a tremendous need for accessing the main challenges affecting the advancement of women's careers, as the number of women in leadership positions continues to decline (Cook, 2016). Women are still pushing to reach the top; they are faced with a range of challenges that many of their male CEO (Chief Executive Officer) counterparts do not understand (Correll, 2016). These are the issues that are preventing many women from achieving their goal of becoming a leader at their company, and it is diminishing their ability to get ahead in business. Previous studies show that women do not face barriers to enter the workplace, but they do face multiple obstacles when it comes to advancement. Women tend to meet more resistance and more isolation as they move up the ranks (Holtzblatt and Marsden, 2018).

\subsection{Research Question}

Therefore, the research question this study seeks to answer is:

1. What are the challenges affecting women's integration in leadership positions in the technology industry?

The ultimate goal of this study is to serve as a benchmark for measuring future progress in increasing female participation, to identify gaps in the current literature and areas for future research. Understanding these issues will greatly aid organizations to increase women's roles along the corporate ladder. Women, men and organizations can work together to improve female participation levels throughout the corporate hierarchy. As more and more women continue to enter the business world and experience the obstacles and elements that men do not face, solutions to these hurdles must be found. 
The researcher intends to achieve the over-arching aim of the study by examining the following specific objectives:

- To understand women's experiences in the technology industry.

- To provide an overview of the main challenges faced by women in the technology industry.

\section{LITERATURE REVIEW}

This section presents a review of literature pertinent to this study, which includes a theoretical foundation, stating the key theory that sustains the study, as well as the conceptualization of the key terms used in this study. This is followed by a historical discussion describing the different barriers faced by women in the past, and the advantages of integrating women in leadership positions. Lastly and equally importantly, a critical discussion of the previous and current challenges identified in the past, as well as recent literature, are included.

\subsection{Theoretical foundation}

This qualitative study is based on implicit leadership theories (ILTs). The research on implicit theories highlights the power of people's beliefs to determine their experiences and their behaviour. According to Tavares, Soral, Goldszmidt, and Araujo (2018), in this model, leadership is seen as a cognitive category in memory. Organized hierarchically, the theory implies that individuals are probably unaware of their biases when they evaluate a leader. The content of ILTs may help us to better understand leaders' gender and work context as possible barriers when it comes to the appreciation of different leadership attributes. Men and women are implicitly expected to perform and behave in specific ways, and this may be one of the reasons why women are still facing some difficulties in rising in leadership positions (Öztürk, Abdülkad Varoglu, and Varoglu, 2017). Previous researchers report that the scarcity of women at the top management levels of organization is related to a gender bias evaluation, as women tend to be regarded as incapable of pursuing leadership positions, even though there are more similarities than differences in leadership styles between women and men (Magsaysay and Hechanova, 2017; Heilman, 2002; Nichols and Erakovich, 2013).

According to the implicit theory of gender expectations, stating how women and men should be and behave, it can result in a devaluation of their performance (Thoman and Sansone, 2016). This consistent disparity needs to be addressed by identifying the underlying mechanism embedded in organizational structures that portrays women as less suitable for senior leadership positions than their male counterparts, although evidence suggests that there is no substantial gender difference in leadership styles or behaviors. As stated earlier in this section, this study aims to identify these challenges, and to find solutions for this 
problem. Moreover, Öztürk, Abdülkadir Varoglu, and Varoglu, (2017) argued that this theory, ILTs, will contribute to the development of a global leadership model that will help to reduce the challenges and barriers in the technology industry. Barriers such as lack of mentors, female role models, and gender discrimination in the workplace need further investigation. Overall, this theory enables the researcher to explore the main challenges that women face and it could be applied in the technology industry, focusing on technology companies to improve growth opportunities and the unequal pay, and invest more in female mentors, so that young females could actually relate more to the industry (Haupts, 2015).

\subsection{Conceptualization}

The following are the key concepts of the study:

1. Leadership: is the ability of an individual or a group of individuals to motivate and guide the other members of an organization (Antonakis and Day, 2017). Leadership refers to a high-level position in an organisation, where the leader provides guidance and influences its followers to achieve a common goal (Klenke, 2016). In the technology industry, leadership positions are mainly occupied by men, as the industry tends to be male- dominant. The term will be used several times in this study, as it focuses on the challenges of integrating women in leadership positions.

2. Technology industry: is a type of business entity that focuses primarily on the development and manufacturing of technology or providing technology as a service. It is a business services company that uses proprietary technology to deliver its products and services (Aydalot, 2018)

3. Challenges: in the context of this study: challenges can be defined as several social barriers, and issues that make it difficult for an individual to perform in their full capacity (Johnson, 2017).

4. Integration: Consists of bringing people or groups with particular characteristics or needs into equal participation in or membership of a social group or institution (Brewster, 2017).

5. Discrimination: Refers to the unequal or unfair treatment of a person based upon personal characteristics, in the technology industry (Glass and cook, 2016).

6. Glass ceiling: An unacknowledged barrier to advancement in a profession, especially affecting women and members of minorities in the technology industry (Glass, and Cook, 2016).

7. Barriers: A circumstance or obstacle that keeps people or things apart or prevents communication or progress, in the technology industry (Vivek, 2016). 
International Journal of Innovation, Creativity and Change. www.ijicc.net

Volume 15, Issue 4, 2021

8. Leadership positions: This refers to middle and top-level management positions in an organisation, in the technology industry (Waldring, Crul and Ghorashi, 2015).

\subsection{Literature Review}

\subsubsection{Historical Background}

According to Eagly et al. (1992), the meta-analysis of the Goldberg paradigm experiments is a global experiment. It took place more than thirty years ago, but a more recent test of the paradigm showed that it continues to replicate. This paradigm handles a lot of tricky confounds, aspects related to workplace treatment, and gender bias. The Goldberg paradigm consisted of several experiments where groups of men and women had to evaluate an article written by a man, and then researchers asked men and women to judge the same content, but where the content was written by a woman. The results all over the world were similar, whereby participants rated the very same words higher coming from a man than from a woman (Donovan, 2014). Thus, it demonstrated that female leaders received less favourable evaluations than their equivalent male counterparts in male-dominated leader roles but were equally evaluated in roles that were not male-dominated.

This could be another challenge that needs to be addressed. Because higher levels of authority and higher wages are concentrated in such environments and are controlled primarily by men; this prejudice is highly consequential for women's advancement. In contrast, Martin and Barnard (2013) explored the experience of women in male-dominant occupations, by using a grounded theory inquiry. Martin and Barnard (2013), concluded that the challenges women face in the technology industry emanate from traditional gender hierarchies that until now prevails in our society. They defend the fact that the household unit still has a traditional structure that makes men the dominant gender in this industry (Martin and Barnard, 2013).

However, a gender analysis of the employees working in the technology industry in South Africa needs to be conducted in terms of Ufo and Ndinda, (2012)'s research, and in doing so, it will be possible to identify the key areas that need to be redressed in breaking the gender gap in to management. Ufo and Ndinda (2012), believe that it makes good business sense for companies to include women in leadership. On the other hand, Skaggs, Stainback and Duncan (2012) used a multi-level dataset to find the reason why women have some barriers to ascend to top-level management positions. The results show that women are more likely to be in management positions when employed in young, large, and managerially intensive workplaces.

This is a topic that needs further investigation, as women do not need to be young to be able to aspire in the workplace. Such mind-sets tend to devalue older women, so it is important to explore the underlining reason for such a mindset. Overall Skaggs, Stainback, and 
Duncan's (2012) research findings require more investigation, and even though the research was not generalized, it could provide negative outcomes for women in the workplace ( Skaggs, Stainback, and Duncan 2012). For example, women who decided to enter the industry after age 35 could easily face such discrimination because of their age. Therefore, the data set can be used to investigate the underlining assumption of this issue as it could also lead to challenges for women.

By the same token, Frisby and Brown (1991) surveyed 30 women, working in senior executive positions in leisure-oriented organizations in order to analyse the experiences and struggles in their way to the top. According to the findings, the most common challenges encountered by women in their career advancement involves family issues, as women tend to interrupt their career due to pregnancy, lack of mentors and role models and support to promote women in senior executives' positions (Frisby and Brown,1991). Women are still being neglected, and underestimated, and participants even reported gender discrimination, stereotyping, and exclusion from male-dominated industries (Frisby and Brown, 1991).

Based on these findings Frisby (1992), conducted a follow-up study, to understand more comprehensively the challenges faced by women in male-dominant industries. The article consisted of several factors reported by middle management women towards their career development. Factors consisted of gender discrimination (unfair treatment because of gender), pay equity (unequal pay for the same position), and once again sexual harassment (Frisby,1992). Frisby and Brown (1991)'s article adds value to this study as it is related to the topic, and it is important to explore all those different factors and challenges faced by women to understand how it affects their career advancement.

Moreover, according to Ashcraft, Mclain, and Eger (2016), another challenge reported by women is the lack of mentoring opportunities from male superiors. For instance, the lack of female mentors and role model as discussed by Frisby and Brown1991) makes it very difficult for women to perform at the highest potential as they also face challenges in the course of the mentoring relationships. Cooper Jackson (2001) argues that without role models in leadership positions they do not have a source of inspiration, or a $t$ sisterhood environment because they are surrounded by a male-dominated culture. Therefore, because women lack opportunities for role modeling or mentoring relationships, they often fail to plan their career advancement (Frisby and Brown, 1991; Cooper Jackson, 2001). Ashcraft, Mclain, and Eger (2016) also support that women are subjected to sexual harassment and based on previous articles this is one of the main challenges faced by women in the workplace. Therefore, it is clear that previous studies attempted to explore this issue, but women are still facing them, so this study aims to explore those challenges in a deeper manner, to provide an in-depth understanding to society and organizations. 


\subsubsection{Advantages of having women in leadership positions}

By exploring these advantages, it could provide a positive overview of how effective business can be with women in leadership positions. Although the main objective of this study is to explore the challenges of integrating women in leadership positions, it is also important to provide an in-depth understanding of the advantages of having women in leadership positions (Powell, and Chang 2016). According to Patel and Buiting (2013), many institutions are now recognizing that women growing in affluence and influence can no longer be ignored, and the article points out the importance of having women in leadership positions and how they could contribute in the organisation. This is related to the research topic, as there is no doubt that women's leadership styles have been valued, but the glass ceiling remains huge, and it is important to address this issue, thereby encouraging organisations to invest more in gender diversity (Patel and Buiting, 2013). The article focuses on different ways to increase women's participation in decision making positions, and it would be useful to apply some of those strategies in this study, as the importance of integrating women in a leadership position is one of the key objectives.

Additionally, an article by Eaglya and Carli (2003) also defends the need for women in leadership positions. The article states that women are more likely than men to lead in a style that is effective, contrasting most of the theories of leadership (Eaglya and Carli, 2003: 810). In their research analysis, the findings of Eaglya and Carli (2003) showed that women have advantages in typical leadership styles, and their research would add more value to this study, as it is very important to explore those advantages to integrate more women in leadership positions in the technology industry. By the same token, Kodama, Takao, and Naomi (2017), also defends that strengthening women's participation in the ICT sector is important, and they described three reasons why. Firstly, it could increase employment opportunities for women and enhance gender equality, breaking the glass ceiling. Also, it could bring more benefits for their communities, and could help to address the supply and demand in the technology industry (Kodama and Takao, 2017; Chang and Mei, 2016; Hardey, 2019). Even though these articles explored a similar issue, some areas still need some clarification, such as the actual benefits of integrating women in leadership positions, how it could benefit their community and to which extent it could help to break the glass ceiling.

Overall, their analysis process is doable, therefore the same analysis could also be used in this study but with different approaches, such as a thematic analysis instead, to provide more reliable information to measure the results and see if they are consistent enough. In addition, an article conducted by Burgess and Tharenou (2002), summarized some of the reasons why women are needed in leadership positions, how more women could be appointed for these jobs and the actions that organisations could take to help increase female representation in leadership positions. 
The very first point of discussion that is linked to this study, is the need for change in policies and procedures of those companies recruiting leaders. Women are becoming more active users of technology and researchers have identified several strategies very useful for companies to appoint women to boards and several activities that technology companies could adopt (Burgess and Tharenou, 2002). Secondly, expanding women's access to technology industries, would advance significant economic opportunities for women and their families, as well as their communities; the technology industry has a shortage of skilled workers and it would be beneficial for both sides if women were included in these industries. As they are becoming more interested and active users of technology, their participation in developing and designing products will enhance technology relevance for women as consumers (Powell and Chang, 2016).

In contrast Kodama and Takao (2017) assert that more clarification of the benefits of having women in leadership positions was needed. Powel and Chang (2016), explained in detail the benefits, stating the need for economic opportunities for women and their families as well as the benefit for the technology industry. Furthermore, according to Powell and Chang (2016) data were collected from the public and private sectors in the United States, aiming to address the multiple barriers women face in undeveloped countries. Their findings were similar to Martin and Barnard (2013), where traditional patterns were found as the main problem leading to the glass ceiling.

\subsubsection{Current challenges of integrating women in leadership positions}

According to Ashcraft's (2016) study, two primary challenges have resulted in the lack of women in leadership positions in the technology industry. The reasons are societal influences and biases, and workplace systems. According to Madsen, (2012), there is a manufactured perception that women are not suitable for technology-based roles assuming that they will not be able to bring anything to the company if they were in leadership positions. This has resulted in the poor statistics of women in technology roles; technology workplaces carry the same biases that have existed traditionally. Madsen's article highlights the issue's overall problem, purpose, the approach used, and its relevance to human resource development (HRD) and practice (Madsen, 2012).

One of the most common and well-known barriers to career advancement is that of the selection process used by most companies. As indicated previously, the pool of women that are qualified for promotion to executive positions is quite small and therefore women simply cannot be promoted. According to Abalkhail and Allan (2015), 82\% of firms state that a lack of general management skills and line experience was a major contributing factor in their decisions not to promote women. Another rationale is that existing top management positions are held by men who tend to promote other men who are like themselves (Van Vianen \& Fischer, 2002). 
Globalization also presents many new barriers for women. Senior-level managers and top executives now have even more responsibility and higher expectations than before. Due to the time pressures and relocations of many businesses, top executives have had to move to new towns, cities, and countries. This presents a large barrier for many women with families and a working spouse or significant other (Harrison, Leitch and McAdam, 2018).Moreover, Glass and Cook (2016), conducted research focusing on the advancement of women in scholarships, by using different analysis, to understand under which conditions women are promoted to top-management positions.

Glass and Cook (2016) explored the different opportunities and challenges that women tend to face post promotion. The data collection method used in their study consisted of a comparison of the career trajectories of all women who have worked as chief executive offices in Fortune 500. The data was gathered from in-depth interviews with women across different industries. Glass and Cook's (2016) findings indicated that women tend to be appointed to higher risk leadership positions, as compared to men, and they also have a lack of support and authority problems to reach their goal (Glass and Cook, 2016).

In-depth interviews provide different points of view. This data collection method can also be used in this study, to analyse all the women who have worked in top management positions in technology companies in SA, because they are the ones who can provide more reliable information based on their experiences in the company. However, this masculine work environment may induce different expectations regarding leadership and their attributes, and one of the limitations could be the generalizability of the reported observation.

Another key article that adds value to the study is Stamarski and Hing (2015) which portrays gender inequality as a self-reinforcing system that can perpetuate discrimination. According to Stamarski and Hing (2015), important levers for reducing discrimination were identified.

They propose a model to understand gender inequalities at work. The model is not longitudinal and has a time frame because they only focus on women's experiences of discrimination. The model derives from previous research conducted in a male dominant industry. It is noted that the technology industry is also a male dominant industry, so a similar model could also so be done in other tech companies, to access the challenges that women face in this industry. Moreover, the model could be used to reduce the gender discrimination in organisations, by delineating a link between the level of stereotypes, social barriers in decision making positions as well as the likelihood of making gender-biased decisions when electing leaders.

Furthermore, a meta-analysis of experimental studies also revealed that women in leadership positions tend to receive an unfair performance evaluation comparing to men (Eagly et al., 1992; Heilman and Okimoto, 2007; Rudman et al., 2012). The issue tends to 
amplify when women perform in a male dominant industry and when they perform in male type jobs, they tend to be evaluated more negatively and are less likely to be recommended for jobs (Avolio, 2014). Moreover, BogacKanadli, Torchia, and Gabaldon (2018) describe the negative effect of social barriers in an organisation. Stemming from the re-categorization theory, they have examined the extent to which board directors enhance the influence of women when they are the minority in top management positions (BogacKanadli, Torchia and Gabaldon, 2018).

BogacKanadli, Torchia, and Gabaldon (2018) found a positive relationship that suggests the board chairperson leadership efficiency and a good working atmosphere of openness increase women's participation in decision making. A good working environment is essential for the employees, and some of the difficulties in the technology industry faced by women include the heavy atmosphere of pressure. However, BogacKanadli, Torchia and Gabaldon, (2018), discussed different ways to increase women's participation in decision making positions, such as the creation of an atmosphere of openness, where women are evaluated according to their skills and capability as well as the ability to lead.

According to the articles discussed above, previous researchers attempted to deal with the gender gap issue for decades, and several authors identified several challenges faced by women in the workplace, such as gender discrimination, pay equity, sexual harassment, family issues, lack of opportunities, and support form senior executives to promote women. But the underlying reason for such an issue remains unclear. For this reason, it is important to conduct this research, as it would contribute to the existent body of knowledge, by exploring these challenges in a more efficient manner, and understanding the challenges that women face in technology companies. As the advancement of women is compromised because of these challenges, it is important to access them these challenges to understand how they affect women towards their career advancement in the technology industry. Overall, by using a qualitative research approach, this study aims to fill this gap and go much deeper to access also the advantages of having female leaders in the technology industry by gathering information that is crucial to explore the challenges that women face in the technology industry, by conducting personal interviews, and listening carefully to women's experiences and struggles in Tech companies.

\section{METHODOLOGY}

In this chapter, the research methodology used to conduct this study is presented, beginning with a brief discussion of the research approach and paradigm, unit of analysis, population and sampling method. A detailed explanation of the methodology used follows, together with the methods used to collect and analyse the data. 


\subsection{Research approach and design}

An exploratory qualitative approach was chosen for this study. This approach was chosen because the study seeks to provide an in-depth understanding of the main challenges attached to the integration of women in leadership positions in the technology industry. This requires a researcher to understand women's experiences through personal interviews, rather than the use of quantitative methods. Qualitative research enables the researcher to ask broader and more open-ended questions that cannot be quantified, because this approach involves more in-depth questioning (Jackson, 2015). Using the qualitative approach, the research was conducted to determine the nature of the problem, without providing conclusive evidence; instead, it provides a better understanding of the problem under study. Hence, the qualitative research approach appears to be the most useful and suitable approach for the purposes of this study.

A phenomenology design was chosen. Phenomenology is a qualitative research design that is used to describe how human beings experience a certain phenomenon (Stienstra, 2015). This particular type of research design was chosen because this study attempts to set aside biases and preconceived assumptions about women's experiences, feelings and responses related to the challenges they face in the technology industry. It allows the researcher to delve into the perceptions, perspectives, understandings and feelings of the participants, who have experienced or lived through the phenomenon or situation under study. Therefore, phenomenology design consists of direct investigations into and descriptions of phenomena as consciously experienced by people living through those experiences (Hoffding and Martiny, 2015). It is typically conducted using in-depth interviews of small samples of participants. Overall, from a phenomenological viewpoint, the subjective experience of each woman working in technology companies was carefully examined for meaning and understanding. Participants' experiences were explored, and the researcher then generalised the phenomenon from the perspective of those that have lived through the experience (Padilla-Díaz, 2015).

\subsection{Research Paradigm}

The research paradigm chosen for this research study is interpretivism. Based on research from various scholars, this paradigm allows researchers to view the world through the perceptions and experiences of the participants (Bryman, Stephens and Campo, 1996). In this way, the researcher is able to use the participants' experiences to construct and interpret their understanding from the data gathered. Clearly stated, this paradigm has been supporting researchers in terms of exploring different contexts by interpreting the perception of participants. This study seeks to explore the experiences of women in the technology industry, and to deeply understand the challenges they face and the importance of integrating women in leadership positions (Mackenzie and Knipe, 2006). As it is very important for the researcher to engage directly with the participants, the interpretivism 
paradigm, which allows for an interaction between the researcher and the participants, is essential. In this case, the term "participants" refers to women who have previously worked in, or who currently occupy top management positions in the technology industry. Interpretivism enables the researcher to gain a broad view of their experiences and perceptions, and an in-depth understanding of their relationships and the social barriers and challenges they face in the work environment (Mackenzie and Knipe, 2006:197). In addition, this paradigm allows the researcher to explore and accept different points of view from various individuals and groups (Thanh and Thanh 2015). Each woman in the technology industry has different experiences and challenges, and it is important to access them as they will be used to construct and interpret the gathered data.

\subsection{Unit of Analysis}

The unit of analysis is the major entity being analysed in the study. It refers to the "who" or the "what" that needs to be analysed (Barquero, Bosch and Gascón, 2019). As this research paper aims to explore the challenges of integrating women in leadership positions in the technology industry, the researcher concentrated on women, as they are the main subject of this study. The unit of analysis can therefore be defined as women working in leadership positions in technology companies.

\subsection{Population}

A population is defined as all elements (individuals, objects and events) that meet the criteria for inclusion in a study (Bezuidenhout, 2015). The population of the study was women who had previously worked in top management positions in technology companies, and those who currently occupy these positions. For this reason, the researcher selected women between the ages of 24 and 58 who work in software companies in leadership positions. The researcher wanted to access women who come from different countries, but who work in the same type of technology companies, to explore the challenges faced during their career advancement.

\subsection{Sampling method}

The sampling method used was the non-probability population sampling method because it is the most helpful for exploratory stages of studies. Subjects are chosen to be part of the sample in non-random ways (Marshall, 1996). This sampling method was chosen because it allows the research participants to recruit other participants for the study (Emerson, 2015). It proved difficult to find women who were prepared to participate in the study, particularly women working in leadership positions in software companies. Most of the potential participants, although working in the technology industry, were not in leadership positions. For this reason, the sampling method was used as it allows the researcher to reach 
populations that are difficult to sample when using other sampling methods, for example; the convenience sample (Etikan, Musa and Alkassim, 2016).

It is, of course, almost impossible to randomly sample the entire population. For this reason, the sample included two females who work in a software development company, and one who is a former CEO, currently working in a start-up tech company. Two participants were from Angola, and one from the United States of America. Although the sample size is relatively small and does not allow for the findings to be generalised, the data does provide rich insights into the feelings of women working in leadership roles in the technology industry.

Overall, the interviews were conducted with a sample of participants to explore the challenges of integrating women in leadership positions, as well as what it is like for women to work in a male-dominant industry, and to explore how these challenges affected the advancement of the women's careers in the field of technology. As mentioned, it was difficult to find suitable potential participants, in this case, women working in the technology industry, to explore their experiences and opinions on this issue. Some women did not want to come forward and participate in the research, with one of the main reasons being that they did not want their identity to be exposed.

A snowball sampling method was selected for this study for a number of reasons. Not only is it convenient, but it is less expensive than other methods and cost-effective, because the referrals are obtained from a primary data source, with research participants recruiting other participants for the study (Marcus, Weigelt, Hergert, Gurt and Gelléri, 2017).

\subsection{Data collection method}

For this study, data was collected through primary and secondary sources. Primary sources consisted of in-depth semi-structured interviews and published documents. Wutich and Brewis (2019) identify primary data as facts obtained from sources such as telephone interviews, personal interviews and observations. However, it should be clarified that all the information obtained through primary means must contain unbiased facts.

The primary data collection process was carried out through semi-structured interviews with three women working in leadership positions in the technology industry, who will be referred to as Participant 1 (one), Participant 2 (two) and Participant 3 (three) in order to maintain their confidentiality. Semi-structured interviews refer to interviews in which researchers elicit information to achieve a holistic understanding of the interviewee's point of view or situation. This type of interview involves the researcher asking informants openended questions and probing wherever necessary to obtain data they deem to be useful (Nigel, Horrocks and Brooks, 2018). Semi-structured interviews were chosen because participants tend to feel more comfortable, as we are used to interviews in our daily lives, 
such as television interviews, recruitment interviews, etc. (Newcomer, Hatry and Wholey, 2015).

The main advantage of an in-depth, semi-structured interview is that it provides far more detailed information than that which is available through other data collection methods, such as questionnaires (Pathak and Intrata, 2016). Participants can easily express their emotions and experiences through an interview as it provides a more relaxed atmosphere in which to collect information and helps to facilitate rapport and empathy, to gain rich and interesting data (Malterud, Siersma and Guassora 2016).

Interviews for this study lasted between 15 to 20 minutes and were conducted via Skype for the participants' convenience and to cater for any time constraints. The interviews were conducted on a one-to-one basis, on three different dates and at three different times. The interview questions were designed for the same objective of the paper, namely, to provide answers for the formulated research question. The participants were asked the same set of questions, in the same order as prepared. (See Appendix, Interview schedule, page 40). This data collection method enabled the researcher to understand the challenges that women in the technology industry face when it comes to the advancement of their careers.

\subsection{Data analysis method}

A qualitative research approach enables the researcher to see the world from the participants' experiences and perspectives. One of the most important aspects of any data analysis process is that it is real and true to the participants (Jackson, 2015). By employing this approach, the researcher was able to understand the phenomenon based on the participants' experiences, how they feel about it and how it affects their performance (Collis and Hussey, 2014).

Qualitative data analysis involves reduction, organisation, interpretation and substantiation of data (Bezuidenhout, 2015). By using qualitative thematic analysis, the researcher was able to gain insight and knowledge from the data gathered. This method enables researchers to develop a deeper appreciation for the group or situation they are researching (Nowell, Norris, White and Moules, 2017). By using thematic analysis to distil data, the researcher was able to determine broad patterns, allowing for more granular research and analysis.

This data analysis method is highly inductive: themes emerge from the data that is gathered and are not imposed or predetermined by the researcher (Nowell et al., 2017). Moreover, all the data collected from interviews was accurately recorded by a voice recorder device, before being documented and labelled with the participants' names and the dates on which the data was collected, to ensure a clear and detailed record (Bernard, 2017). The interviews were recorded with the permission of the participants, in line with the ethical guidelines of IIE. Therefore, data was collected and prepared through the conversion and transferability 
of raw data collected from in-depth interviews, and the respective records. Verbatim transcripts of the interviews were then analysed by the researcher independently in the first instance, to highlight the major themes. In order to ensure reliability, the researcher codified, defined and analysed the information, through a very close examination, to identify themes and decide how to break them down into parts, to facilitate patterns, numeration and definition. Moreover, codes were developed from this pattern and processed as coding (open, axial and selective).

Following this labelling and coding, all the data was analysed so that similarities and differences could be recognised. Responses from in-depth interviews were entered into a computer for them to be coded, counted and analysed. Moreover, the coding scheme was tested to check its consistency. Narrative aspects such as the physical surroundings, the characters of the participants, the social interactions between the different participants and their emotions, beliefs and attitudes were all considered. The essential meanings of these narrative aspects were kept, even when several of these aspects were changed. As the researcher worked with the rich descriptive data, common themes or essences began to emerge. This stage of analysis involved a total immersion for the researcher, to ensure both a pure and thorough description of the phenomenon. To conclude, the themes and categories were interpreted according to the existing theories, previous studies and the researcher's sense of meaning and were supported by computer programs, such as a coding analysis toolkit.

\section{FINDINGS}

This section of the research reports on the findings of the study. The responses to the interview questions obtained from the three interviewees working in leadership positions in the technology industry are summarised and presented in this section. Moreover, the trustworthiness of the research paper seen in terms of its credibility, transferability, dependability and confirmability is also described.

The interview questions were answered and broadly discussed, with further follow-up carried out via email for clarification. At the beginning of the interviews, it was not always easy for the participants to explicitly express their experiences in the technology industry. Later, perhaps when they became more comfortable with the interview process, they were able to talk more openly about their experiences. The interviewees discussed the various challenges they face in the workplace in the technology industry, such as the absence of female mentors, the lack of support from male colleagues and the challenges of working in a male-dominated industry. Through the data analysis process, three main themes emerged: gender discrimination, work environment and sexual harassment. These themes encapsulate each one of the participants' struggle to deal with the exasperation they have experienced in the workplace: which encompasses a range of feelings including disappointment, offense, vulnerability and rage, all of which result in feelings of frustration. Themes will be 
discussed in detail according to the participants' experiences and feelings at a later stage in the study, after which the results will be interpreted and discussed.

\subsection{Gender discrimination}

The interviewees argued their successes were left uncelebrated compared to those of their male colleagues. This lack of recognition impacted upon the respondents' existing belief that there is differential treatment of men and women in the workplace. Female leaders in male-dominated leader roles reported that they received less favourable evaluations than their equivalent male counterparts but were fairly evaluated in roles that were not maledominated. This finding extends the current understanding of why women feel marginalised, through the identification of the important role that recognition plays in career advancement. Participant 2 reported that when a woman is trying to achieve a certain position in a company, she will always need to prove her competence and ability to perform a task in a number of ways. Two participants reported that men, on the other hand, are not required to do so. This is an important finding in the understanding of the issues that have been affecting the advancement of women in the technology industry.

Participant 3 reported that "in order to survive in the technology industry, women need to stand up for themselves and be their [own] hero, because nobody else is going to do it for you," and felt that the technology industry is very aggressive and male-dominant. Further, a recurrent theme in the interview data was the gendered practices within the technology industry. Participants reported that they were not protected from discrimination at any stage of employment and there was evidence that male networks dominated daily working practices. As a consequence, women reported feeling excluded. Participant 2 said: "Your work is not taken seriously just because you are a woman." From these results, the impact of exclusion was perceived to influence career-enhancing opportunities such as inclusion on research projects and software development. It also became evident that in a traditionally male-dominant industry, such as the technology industry, some men dislike women employees as they perceive them to be a threat.

\subsection{Working environment}

The study confirmed the findings related to the lack of mentoring opportunities available from a male superior. Participants reported that the working environment in the technology industry is very competitive. Participant 1 reported that when men see that a woman can execute the same task as they can, they feel insecure and refuse to share any kind of knowledge with her, leading to the competition becoming fiercer. Participant 2 reported that when she needed specific information about software, her male colleagues refused to supply it, because they are afraid that by teaching her, she may become better than them in that specific area. Other participants argued that while working in a male-dominated sector can 
be challenging, a lot depends on your work environment and the kind of environment that your office provides you with.

These results provide evidence that it may not be easy for women to work in the technology sector, as working in a field dominated by men can be very competitive and women may experience various forms of aggression, especially from those men who recognise their potential and feel threatened by the possibility of having their positions taken away from them. Participants reported that the lack of support and inspiration for female leaders makes it difficult for women to enhance their career advancement. This result highlights the fact that little is known about the shortage of female mentors and role models in the technology industry and the multitude of the challenges this causes.

Despite their organisations having policies in place to mitigate gendered practices, the respondents reported experiencing blatant gender discrimination and social barriers. Furthermore, interviewees reported they were not well-informed regarding promotion procedures and were discouraged from attempting to align their career trajectory to the next level of decision-making positions. This finding shows that women in the workplace are still being neglected and underestimated and concurs with previous literature, which maintains that women are not fairly promoted and tend to be appointed to low-ranking positions while having to depend on the approval of male superiors in terms of hiring and career advancement.

As mentioned in Chapter 1, the motivation behind this study lies in the fact that while society is constantly progressing, it is still failing in the area of gender equality. This is particularly evident in the technology industry, where women are highly underrepresented. It is known that the technology industry is a male-dominant industry, therefore, the lack of females in higher positions makes it harder for women to gain entry into this sector, as well as relate to it. The results confirm that the working environment in the technology industry is very competitive and that certain males see their women colleagues as a potential threat. For this reason, women lack sufficient support as they tend to be underestimated and discriminated against. The results show that these types of challenges usually start at high school and university as reported by participant 2 .

Therefore, both educational institutions and technology companies should condemn all kinds of gender discrimination from the earliest stages. More gender diversity should be encouraged in the technology sector by the hiring of more female mentors, so that young females can actually have a role model and be able to relate to the industry better. Previous studies have reported that even though it is against the law to discriminate against anyone in the workplace because of their gender, women experience the technology industry to be an aggressive one where they are treated unequally, discriminated against and regarded as underqualified (Madsen, 2012; Waldring, Crul and Ghorashi, 2015). 


\subsection{Sexual harassment}

The results further revealed that conversations in the workplace are rife with sexist connotations. Participant 3 stated: "People ask you out for a coffee and casually mention, 'Oh, but you look so beautiful, and I want to see you,' you know. And I don't see that happening with men a lot." Other participants reported that even the compliments they received from their male colleagues were not ethical, resulting in an atmosphere of disrespect that in a certain way interfered with their performance, by acting as a barrier to the advancement of their careers. Another important finding was that in some situations, a woman who is being sexually harassed in the workplace can risk losing the opportunity for a promotion, or even her job, if she refuses to give in to the sexual demands of someone in a position of authority. In other situations, the unwelcome sexual conduct of co-workers makes the working conditions hostile and unpleasant - placing indirect pressure on the victim to leave her job. Participant 2 reported feeling demoralised by sexual harassment on many occasions and noted that it affected her job in many different ways, while among men, it served to reinforce stereotypes of women employees as sex objects.

\section{INTERPRETATION AND DISCUSSION}

In this chapter, discussions based on the findings of this research paper in light of the literature review developed in Chapter 2, which centred around the purpose of the study as well as the formulated research question and interview questions, are interpreted and described in detail. The purpose of this study is to assess the challenges of integrating women in leadership positions in the technology industry. To reach this objective, a research question was formulated. Using a phenomenology approach, the researcher conducted semistructured interviews with three women employed in leadership positions in the technology industry and used the collected information as a primary source of data to come up with findings.

The findings indicate that women face a lot of pressure to fit the requirements of working in the technology industry. The main challenges reported by the participants are gender discrimination, work environment and sexual harassment, with participants reporting that the technology industry is extremely sexist and that women are paid less than their male counterparts. This may be the cause of the disparity between women and men when it comes to achieving leadership positions in the technology industry. These challenges make it very difficult for women to advance their careers in this sector, as it impacts on their ability to perform. The present study confirmed the findings of Avolio (2014), who reported that gender discrimination is one of the main issues affecting women in the workplace; being unrecognised and always having to prove that they are qualified and capable of holding a certain position in a company results in a lack of confidence, and subsequently affects their ability to perform a task. Further, the present findings confirm Frisby and 
Brown's (1991) argument that the lack of female mentors makes it very difficult for women to perform to their full potential.

Another key finding of this study, centred on the lack of female mentors, supports the argument of Ashcraft, McLain and Eger (2016), which states that the lack of role models in the technology industry make it very difficult for women to advance their careers, as men tend to support other men and sometimes feel insecure when women show the potential to occupy top-level positions. The results lead to a similar conclusion as to that of Aydalot and Keeble (2018), which is that when men see that a woman is capable of executing the same task, the competition increases considerably, as women are required to prove in a number of different ways that they have the ability to execute the task. This environment of discrimination, where women must always prove their capabilities, creates an atmosphere of insecurity and pressure and leads to women not performing as they should, because they are already seen to be incapable. Overall, these findings are in accordance with findings reported by Ashcraft, McLain and Eger (2016), where societal influences and biases, as well as workplace systems, are seen to affect the performance of women in the technology industry.

Further, previous research highlighted gender discrimination (unfair treatment because of your gender) in the technology industry. The results show that gender discrimination is a substantial issue affecting the integration of women in leadership positions in the technology industry (Frisby, 1992; McDonald and Charlesworth, 2016). Technology workplaces carry the same biases that have existed traditionally over time. Glass and Cook (2016) argued that being at the mercy of male superiors deprives women of the material security and independence which could help make resistance to unreasonable job pressures practical. Besides, sexual harassment was mentioned several times, and according to previous research, creates a climate of intimidation and repression. Women who are subjected to harassment endure a lot of pressure and hostility that their male colleagues do not have to face, making it harder for them to compete for a job, or even to perform a task and advance their careers in the technology industry. A similar conclusion was reached by Chizema, Kamuriwo and Shinozawa (2014).

According to the Implicit Leadership Theory (ILT), individuals are unaware of their biases when they evaluate a leader. The content of ILT highlights that leaders' gender and work context are possible barriers when it comes to the appreciation of different leadership attributes (Öztürk, Varoglu and Varoglu, 2017). Participants reported being discriminated against because of their gender and noted that they always felt the need to prove their value and competence in the workplace, in a way man don't. This concurs with the ILT, whereby women are implicitly expected to perform and behave in specific ways in the workplace, and this surely aligns with the results obtained from the interviews. Participants reported the lack of female mentors in top management positions, resulting in mistreatment from their male co-workers. The theoretical foundation of this study highlights that the scarcity 
of women at the top management levels of organisation is related to a gender bias evaluation (Cook and Glass, 2016). Participant 1 reported that women are sometimes depreciated just for being women. Most of the time, they are connotated as being incapable of performing a task, or of holding a leadership position in a company. This aligns with the ILT, which defends the notion that women tend to be regarded as incapable of pursuing leadership positions, even though there are more similarities than differences in the leadership styles of men and women. Therefore, evidence supports the ILT, as the results concur with the arguments made by the theory's various researchers.

\subsection{Trustworthiness}

According to Connelly (2016), qualitative research becomes increasingly recognized and valued, employing the trustworthiness of the research. It must be conducted rigorously and methodically to yield meaningful and useful results. In order for a research report to be seen as important and of a superior standard it is expected that the research has been conducted in a precise, consistent, and exhaustive manner through recording, systematizing, and disclosing the methods of analysis with enough detail to have relevance, credibility and that draws attention from others (Easterby Smith et al. 2012). Moreover, the four major standards for making a judgment on the quality of research are credibility, transferability, dependability, and confirmability (Bryman \& Bell 2015).

1. Credibility: Credibility deals with the internal validity of the research. Credibility is concerned with "the integrity of the conclusions that are generated from research" (Bryman and Bell 2015 pp: 50). It refers to how confident the researcher is in the truth of the research study's findings. Having multiple interviews with three different women working in the Technology industry, getting their perspective, views and experiences are considered as triangulation, and therefore by applying it, credibility could be ensured.

2. Transferability: Unlike credibility, which concerns with internal validity, transferability mainly looks at the external validity of the research. The issue with transferability is whether the outcome of the research could be generalized and could give the same results for other similar types of researches (Bryman and Bell 2015). Connelly (2016: 436) pointed out that transferability is the extent to which the researcher demonstrates that the study's findings can be applied to other contexts. All possible efforts were made by the researcher to show and disclose all detailed information obtained through the interview and from secondary sources. All the information gathered during the interviews were carefully transcribed. Following this, codes and themes emerged during the process of data analysis. Highlighting three challenges, working environment, sexual harassment and discrimination. Both participants reported these three challenges during the interview. Therefore, the chances of having similar results in a similar study are very high. 
3. Dependability: Refers to the degree of neutrality in the research study's findings. In other words, this means that the findings are based on participants' responses and not any potential bias or personal motivations of the researcher (Connelly, 2016). For this study, consideration was taken during the data analysis and findings sections. The researcher ensured that nothing was missed in the research study. any form of bias was highly avoided, the findings were supported by the data collected. All the findings, interpretations and conclusions were carefully examined to determine whether they are supported by the data itself.

4. Confirmability: The point of confirmability refers to the quality of being objective, impartial and free of bias (Bryman and Bell 2015). Connelly (2016) argues that it refers to how broadly the study could be repeated by other researchers, and how the findings would be consistent. In this research paper, the researcher used both internal and external means of information to examine the reliability of the information. Moreover, the research work was completed without any external influence. This is in line with Kirk and Maxwell (1992) argument, which explains that end outcomes need to be free from bias and other external situations that could otherwise possibly influence the final findings.

\section{CONCLUSION}

In conclusion, this section includes the overall concluding points of the research based on the aims of the study and findings are presented. Moreover, the limitations of this study and recommendations for future research are also included in this section. This research set out to extend understanding of the challenges of integrating women in a leadership position in the technology industry. Previous sources have cited the absence of women at leadership positions in the technology industry, and as a result, the number of women in senior roles within the technology industry is proportionally fewer. This study explores some of the reasons behind the prevailing inequity for this purpose, and one research question was formulated to assess the challenges. The formulated research question was successfully answered through semi-structured interviews with three women currently working in the technology industry. It was possible to draw some conclusions based on the results of the data analysis, and a core finding of this research is that at each stage of their career, from recruitment and selection to retirement, women struggle to navigate their careers in a gendered environment.

It was possible to identify the main challenges of integrating women in leadership positions in the technology industry; overall the main conclusion that can be drawn from this study, is that the male-dominated culture led women to feel intimidated and one participant even considered leaving the organisation. Undoubtedly individual perceptions of ability challenge many women. The overarching theme from the study was the lack of career guidance and support from the institution. To navigate their careers to senior positions, 
women were unclear regarding the expectations to gain promotion to advance their careers. The male-dominated culture influences daily working practices and the evidence suggests that exclusion from opportunities for career advancement occurs. The research purpose was reached, as in this paper the researcher has shown the different challenges of integrating women in leadership positions. Challenges such as of lack of support, gender discrimination and sexual harassment in women's lives.

\subsection{Implications for Future Research}

The broad implication of the present research is the contribution to the existing literature on women in leadership, and social barriers by extending the understanding of the challenges women face to reach senior positions in the technology industry. Gender and leadership are issues that affect several industries, such as health, education, business, the restaurant industry, etc. Women leaders contribute positively to organizations, although they remain significantly underrepresented in leadership positions (Chizema, 2014). While the diverse challenges faced by women are well documented, what is less understood are the factors that shape the experience and the impact on their performance?

This research paper provides a deeper understanding regarding challenges to integrating women in leadership positions in the technology industry. This study will raise awareness by informing others about these issues related to women in technology. This paper is a single phenomenological approach, which is compiled using qualitative methods for future researches, the author suggests that future research should consider the potential effects of the challenges of integrating women in leadership positions more carefully. For example, future research is needed to delimitate the extent to which these challenges affect women performances, and how to mitigate them, because having your employees performing at their full capacity and without social barriers and challenges will enhance the performance as well as the organisational goals.

Regardless, future research could continue to explore issues related to gender discrimination and the lack of female mentors in the technology industry. There are a lot of technology companies where women face numerous challenges around the world, and these challenges are not addressed properly.

\subsection{Ethical implications}

Research ethics involves requirements on daily work, the protection of the dignity of subjects and the publication of the information in the research. However, ethical challenges can be found in every stage of the study, from design to reporting. To obtain an ethical clearance and to protect the participant's integrity it is important to ensure that the study complies with the ethical considerations. These include confidentiality and informal consent, researchers' potential impact on the participants and vice versa. Qualitative 
research, for instance, involves the interaction between the researcher and participants, and it can be challenging as both are personally involved in some stages of the study, such as the data collection method phase.

Therefore, the formulation of specific ethical guidelines was essential, to enhance the ethical consideration in this study; To collect information, a consent form was obtained from the participants beforehand. The consent form included all the relevant information related to this study. Participants were informed about all the procedures and possible risks involved in this research, and how the safety would be protected. For their safety, and convenience interviews were conducted via skype, confidentiality was assured as the participants did not want to be exposed at any stage of this study. Participants were assured that the information would not be made available to anyone who is not directly involved in the study. All the information collected through the interviews was protected; and as requested by the participants, no descriptions such as names and ages were included in this paper. The researcher had to use terms such as "Participant one" to protect the participant's privacy. Further, any kind of risk or harm was avoided, participants were not put in any kind of dangerous situation and were not forced or persuaded to participate in the research. The researcher did not falsify and distorted any information. Appropriate research methods were used, interview responses were transcribed by the researcher, and coded, following up by thematic analysis to identify the key themes that emerged during the interviews. Any type of misleading information, as well as the representation of primary data findings in a biased way, was avoided. Lastly, any type of communication concerning the research was done with honesty and transparency, each participant was fully informed, further information was given during the interview, to clarify any doubts and outline the purpose of this study.

The use of offensive, discriminatory, or other unacceptable language was avoided in the formulation of Interview questions, all participants were treated with respect, interviews were conducted according to participant's disponibility. Overall, this study followed the IIE ethical consideration and was only conducted after the IIE permission. The confidentiality of the subjects was protected. Several strategies were developed to ensure the protection of all personal information, for instance, secure data storage methods, removal of identifier components, biographical details amendments and pseudonyms. Moreover, this study focused on avoiding any kind of bias during the research process, such as design, data analysis, and interpretation. Therefore, the work was reviewed carefully and critically to ensure that the results are credible.

\subsection{Limitations}

As with most studies, the design of the current study is subject to limitations such as the research approach. Qualitative research is helpful when it comes to understanding a specific issue. However, this approach is often misused and misunderstood as it uses smaller and more targeted populations and it cannot be generalized. The author is aware 
that the research may have three limitations. The first is, due to a short period in conducting this study, it was not possible to interview a larger number of women working in a leadership position in the technology industry. Secondly, it was a struggle to find participants, some women did not accept to participate because of their unavailability. Time was a constraint as well, as the participants live in other countries and the time zone was too different. Thirdly, as the study was done using a qualitative research method, the author believes that a quantitative approach could have yielded more measurable analysis and conclusions. Also, the quantity of data makes interpretation and analysis timeconsuming; the entire process thus took several weeks.

In addition to these limitations, the sample size in this study is small across a limited range of industries such as education, financial services, retail, and health care industries. Therefore, a more comprehensive study covering a cross-wide range of industries and countries would provide a better understanding of the challenges of integrating women in leadership positions in the technology industry. Despite these limitations, this exploratory research provides avenues for increasing the probability of success of women in leadership positions.

\section{Declaration}

I, Dionisia Cidre, hereby declare that the Research Report submitted for the Bachelor of commerce Honours in management degree to The Independent Institute of Education is my own work and has not previously been submitted to another University or Higher Education Institution for degree purposes. Date: 28 October 2019 


\section{REFERENCE LIST}

Abalkhail, J.M. and Allan, B., 2015. Women's career advancement: mentoring and networking in Saudi Arabia and the UK. Human Resource Development International, 18(2), pp.153168.

Alomair, M.O., 2015. Female Leadership Capacity and Effectiveness: A Critical Analysis of the Literature on Higher Education in Saudi Arabia. International Journal of Higher Education, 4(4), pp.81-93.

Antonakis, J. and Day, D. (2017). The nature of leadership. 3rd ed. Sage Publishing, pp.30-35.

Ashcraft, C., McLain, B. and Eger, E., 2016. Women in tech: the facts. National Centre for Women \& Technology (NCWIT).

Avolio, B.J., Sosik, J.J., Kahai, S.S. and Baker, B., 2014. E-leadership: Re-examining transformations in leadership source and transmission. The Leadership Quarterly, 25(1), pp.105-131.

Avolio, B.J., Sosik, J.J., Kahai, S.S. and Baker, B., 2014. E-leadership: Re-examining transformations in leadership source and transmission. The Leadership Quarterly, 25(1), pp.105-131.

Aydalot, P. and Keeble, D. (2018). High technology industry and innovative environments. London: Routledge, pp.200-230.

Barquero, B., Bosch, M. and Gascón, J., 2019. The unit of analysis in the formulation of research problems: the case of mathematical modelling at university level. Research in Mathematics Education, pp.1-17.

Bass, B.M. and Avolio, B.J., 1994. Shatter the glass ceiling: Women may make better managers. Human resource management, 33(4), pp.549-560.

Bernard, H.R., 2017. Research methods in anthropology: Qualitative and quantitative approaches. Rowman \& Littlefield.

Bezuidenhout, F. d. P.C. C. D. a. R.-M., 2015. Research Matters. Cape Town: Juta.

Brewster, C., 2017. The integration of human resource management and corporate strategy." Policy and practice in European human resource management. Routledge, pp. 22-35.

Bryman, A. and Bell, E., 2015. Business Research Methods (Vol. fourth). Glasgow: Bell \& Bain Ltd.

Bryman, A., 2016. Social research methods. Oxford university press.

Bryman, A., Stephens, M. and Campo, C. à (1996). The importance of context: Qualitative research and the study of leadership. The Leadership Quarterly, 7(3), pp.353-370.

Burgess, Z. and Tharenou, P., 2002. Women board directors: Characteristics of the few. Journal of business ethics, 37(1), pp.39-49.

Chizema, A. (2014). Women on corporate boards around the world. Academy of Management Proceedings, 2014(1), p.11044.

Collis, J. and Hussey, R. (2014). Business research. 4th ed. Basingstoke: Palgrave Macmillan.

Connelly, L. M., 2016. Trustworthiness in qualitative research. MedSurg Nursing, p. 435.

Cooper Jackson, J., 2001. Women middle managers' perception of the glass ceiling. Women in management review, 16(1), pp.30-41. 
Correl, S. and Mackenzie, L. (2019). To Succeed in Tech, Women Need More Visibility. [online] Harvard Business Review. Available at: https://hbr.org/2016/09/to-succeed-in-techwomen-need-more-visibility [Accessed 14 May 2019].

Diversity. Journal of Business Ethics. [online] Available at: https://link.springer.com/article/10.1007\%2Fs10551-019-04116-9 [Accessed 15 Oct. 2019].

Donovan, K., 2014. The Goldberg Paradigm and Elegant Gender Research. The journal of psycology.

Eagly, A. and Heilman, M. (2016). Gender and leadership: Introduction to the special issue. The Leadership Quarterly, [online] 27(3), pp.349-353. Available at: https://www.5050foundation.edu.au/assets/reports/documents/2016-Gender-andLeadership-Introduction-to-the-special-issue.pdf [Accessed 6 Apr. 2019].

Eagly, A.H. and Carli, L.L. (2003). The female leadership advantage: An evaluation of the evidence. The Leadership Quarterly, 14(6), pp.807-834.

Eagly, A.H., Makhijani, M.G. and Klonsky, B.G., 1992. Gender and the evaluation of leaders: A meta-analysis. Psychological bulletin, 111(1), p.3.

Easterby-Smith, M., Thorpe, R. and Jackson, P.R., 2012. Management research. Sage.

Emerson, R.W., 2015. Convenience sampling, random sampling, and snowball sampling: How does sampling affect the validity of research?. Journal of Visual Impairment \& Blindness, 109(2), pp.164-168.

Etikan, I., Alkassim, R. and Abubakar, S., 2016. Comparision of snowball sampling and sequential sampling technique. Biometrics \& Biostatistics International Journal, 3(1), pp.12.

Etikan, I., Musa, S.A. and Alkassim, R.S., 2016. Comparison of convenience sampling and purposive sampling. American journal of theoretical and applied statistics, 5(1), pp.1-4.

Frisby, W. and Brown, B.A., 1991. The balancing act: women leisure service managers. Journal of Applied Recreation Research, 16(4), pp.297-321.

Frisby, W., 1992. Women in leisure service management: Alternative definitions of career success. Loisir et Société/Society and Leisure, 15(1), pp.155-174.

Gallagher, S., 2013. Phenomenology and experimental design toward a phenomenologically enlightened experimental science. Journal of consciousness studies.

Glass, C. and Cook, A. (2016). Leading at the top: Understanding women's challenges above the glass ceiling. The Leadership Quarterly, 27(1), pp.51-63.

Grady, K., 2019. Strengths \& Limitations of Qualitative Research. Emerald Group Publishing Limited, pp. 12-14.

Hardey, M., 2019. Women's leadership and gendered experiences in tech cities. An International Journal, 34(3), pp. 188-199.

Harrison, R.T., Leitch, C.M. and McAdam, M., 2018. Breaking glass: Towards a gendered analysis of entrepreneurial leadership. In Research Handbook on Entrepreneurship and Leadership. Edward Elgar Publishing.

Haupts, T., 2015. Implicit Leadership Theories: Do they differ. Semanticscholar, pp. 1-24. 
Hoffding, S. and Martiny, K. (2015). Framing a phenomenological interview: what, why and how. Phenomenology and the Cognitive Sciences, [online] 15(4), pp.539-564. Available at: http://DOI: 10.1007/s11097-015-9433-z [Accessed 9 Jun. 2019].

Holtzblatt, K. and Marsden, N. (2018). Designathon to Support Women in Tech. Extended Abstracts of the 2018 CHI Conference on Human Factors in Computing Systems - CHI '18.

Jackson, S., 2015. Research methods and statistics: A critical thinking approach. Cengage Learning.

Jogulu, U. and Wood, G. (2006). The role of leadership theory in raising the profile of women in management. Equal Opportunities International, [online] 25(4), pp.236-250. Available at: https://www.researchgate.net/publication/228636260_The_Role_of_Leadership_Theory_i n_Raising_the_Profile_of_Women_in_Management [Accessed 7 Jul. 2019].

Johnson, C. E., 2017. Meeting the ethical challenges of leadership: Casting light or shadow. Sage Publications.

Kanadl1, S.B., Torchia, M. and Gabaldon, P., 2018. Increasing women's contribution on board decision making: The importance of chairperson leadership efficacy and board openness. European Management Journal, 36(1), pp.91-104.

Kato, T. and Kodama, N. (2017). The Effect of Corporate Social Responsibility on Gender Diversity in the Workplace: Econometric Evidence from Japan. British Journal of Industrial Relations, 56(1), pp.99-127.

Kato, T. and Kodama, N., 2017. Women in the workplace and management practices: Theory and evidence.

Kawulich, B. B., 2005. Participant Observation as a Data Collection Method. Qualitative Inquiry: Research, Archiving, and Reuse, 6(2), pp. 76-78.

King, N., Horrocks, C. and Brooks, J., 2018. Interviews in qualitative research. SAGE Publications Limited.

Klenke, K., 2016. Qualitative research in the study of leadership. Emerald Group Publishing Limited.

Lewellyn, K.B. and Muller-Kahle, M.I. (2019). The Corporate Board Glass Ceiling: The Role of Empowerment and Culture in Shaping Board Gender

Mackenzie, N. and Knipe, S., 2006. Research dilemmas: Paradigms, methods and methodology. Issues in educational research, 16(2), pp.193-205.

Madsen, S.R., 2012. Women and leadership in higher education: Current realities, challenges, and future directions. Advances in Developing Human Resources, 14(2), pp.131-139.

Magsaysay, J. and Hechanova, M. (2017). Building an implicit change leadership theory. Leadership \& Organization Development Journal, 38(6), pp.834-848.

Malterud, K., Siersma, V.D. and Guassora, A.D., 2016. Sample size in qualitative interview studies: guided by information power. Qualitative health research, 26(13), pp.1753-1760.

Marcus, B., Weigelt, O., Hergert, J., Gurt, J. and Gelléri, P., 2017. The use of snowball sampling for multi-source organizational research: Some cause for concern. Personnel Psychology, 70(3), pp.635-673. 
Mariwilda, P. D., 2015. Phenomenology in educational qualitative research: Philosophy as science or philosophical science. International Journal of Education Excellence, 2(1), pp. 101-110.

Marshall, M.N., 1996. Sampling for qualitative research. Family practice, 13(6), pp.522-526.

Martin, P. and Barnard, A. (2013). The experience of women in male-dominated occupations: A constructivist grounded theory inquiry. SA Journal of Industrial Psychology, [online] 39(2). Available at: https://sajip.co.za/index.php/sajip/article/view/1099/1324 [Accessed $11 \mathrm{Jul.}$ 2019].

Maxwell, J., 1992. Understanding and validity in qualitative research. Harvard educational review, 62(3), pp.279-301.

McDonald, P. and Charlesworth, S., 2016. Workplace sexual harassment at the margins. Work, employment and society, 30(1), pp.118-134.

Ndinda, C. and Okeke-Uzodike, U., 2012. Present but absent: Women in business leadership in South Africa. Journal of International Women's Studies, 13(1), pp.127-145.

Newcomer, K.E., Hatry, H.P. and Wholey, J.S., 2015. Conducting semi-structured interviews. Handbook of practical program evaluation, 492.

Nichols, T. and Erakovich, R. (2013). Authentic leadership and implicit theory: a normative form of leadership? Leadership \& Organization Development Journal, [online] 34(2), pp.182195. Available

at: https://www.researchgate.net/publication/263189648_Authentic_leadership_and_implicit_ theory_A_normative_form_of_leadership [Accessed 12 Jul. 2019].

Nowell, L., Norris, J., White, D. and Moules, N. (2017). Thematic Analysis. International Journal of Qualitative Methods, [online] 16(1), p.160940691773384. Available at: https://doi.org/10.1177/1609406917733847 [Accessed 18 Aug. 2018].

Öztürk, A., Abdülkadir Varoglu, M. and Varoglu, D. (2017). A Critical Review of Implicit Leadership Theory on the Validity of Organizational Actor-National Culture Fitness. International Journal of Organizational Leadership, [online] 6(4), pp.456-469. Available

at: https://www.academia.edu/38091186/A_Critical_Review_of_Implicit_Leadership_Theory _on_the_Validity_of_Organizational_Actor-National_Culture_Fitness [Accessed 9 Jul. 2019].

Padilla-Díaz, M., 2015. Phenomenology in educational qualitative research: Philosophy as science or philosophical science. International Journal of Educational Excellence, 1(2), pp.101-110.

Patel, G. and Buiting, S. (2019). Gender Differences in Leadership Styles and the Impact within Corporate Boards. [online] NCGS. Available at: https://www.ncgs.org/research/database/gender-differences-in-leadership-styles-and-theimpact-within-corporate-boards/ [Accessed 14 May 2019].

Pathak, A. and Intratat, C., 2016. Use of semi-structured interviews to investigate teacher perceptions of student collaboration. Malaysian Journal of ELT Research, 8(1), p.10. 
Powell, C. and Chang, A.M., 2016. Women in tech as a driver for growth in emerging economies. Council on Foreign Relations. Available at: https://www.cfr.org/report/womentech-driver-growth-emerging-economies [Accessed 6 May 2019].

Reynolds, R. H., 2015. 4 reasons why talented women are shut out of tech. Harvard Business Review, 17 Jun.pp. 17-18.

Rosener, J. B., 1990. Ways Women Lead. Harvard Business Review, pp. 119-125.

Rudman, L.A., Moss-Racusin, C.A., Phelan, J.E. and Nauts, S., 2012. Status incongruity and backlash effects: Defending the gender hierarchy motivates prejudice against female leaders. Journal of Experimental Social Psychology, 48(1), pp.165-179.

Skaggs, S., Stainback, K. and Duncan, P., 2012. Shaking things up or business as usual? The influence of female corporate executives and board of directors on women's managerial representation. Social Science Research, 41(4), pp.936-948.

Sprague, K., 2016. Wanted: More women in technology. Mckinsey, pp. 12-15.

Stamarski, C.S. and Son Hing, L.S., 2015. Gender inequalities in the workplace: the effects of organizational structures, processes, practices, and decision makers' sexism. Frontiers in psychology, 6, p.1400.

Stienstra, J., 2015. Embodying phenomenology in interaction design research. Interactions, p. 20.

Tavares, G., Sobral, F., Goldszmidt, R. and Araújo, F. (2018). Opening the Implicit Leadership Theories' Black Box: An Experimental Approach with Conjoint Analysis. Frontiers in Psychology, [online] 9. Available at: https://www.ncbi.nlm.nih.gov/pmc/articles/PMC5808314/ [Accessed 8 Aug. 2019].

Thanh, N.C. and Thanh, T.T., 2015. The interconnection between interpretivist paradigm and qualitative methods in education. American Journal of Educational Science, 1(2), pp.24-27.

Thoman, D. and Sansone, C. (2016). Gender bias triggers diverging science interests between women and men: The role of activity interest appraisals. Motivation and Emotion, 40(3), pp.464-477.

Vianen, A. and Fischer, A. (2002). Illuminating the glass ceiling: The role of organizational culture preferences. Journal of Occupational and Organizational Psychology, [online] 75(3), pp.315-337. Available at: https://doi.org/10.1348/096317902320369730 [Accessed 12 Apr. 2019].

Vivek, B. (2016). EMPOWERING WOMEN: UNCOVERING FINANCIAL INCLUSION BARRIERS. Advances in Social Sciences Research Journal, 3(3).

Waldring, I., Crul, M. and Ghorashi, H. (2015). Discrimination of Second-Generation Professionals in Leadership Positions. Social Inclusion, 3(4), p.38.

Wutich, A. and Brewis, A. (2019). Data Collection in Cross-cultural Ethnographic Research. Field Methods, 31(2), pp.181-189. 


\section{Annexure: Interview schedule}

The purpose of this interview is to explore the challenges of integrating women in leadership positions in technology industry. The interview will consist of openended questions and will take up to 20 minutes. For the purpose of this study, the researcher will interview 3 women working in tech industry.

1. How it is to work in a male dominant industry?

2. In your opinion how could women contribute if they were appointed in leadership positions?

3. How do you feel about having more men than female in your workplace?

4. In your opinion are women fairly promoted in this industry?

5. Did you ever had any challenges to advance your career in this industry?

\section{Effects on your personal life:}

6. How do you consolidate work and family?

\section{Clearinghouse question: The interviewee's turn}

7. Is there anything I haven't asked about that you think I should know?

8. Is there anyone else you would recommend I speak to?

\section{Closing}

Thank Her for his time. Handshake, goodbye.

\section{Annexure: Explanatory information sheet and consent form for participants}

To whom it may concern,

My name is Dionisia Cidre and I am a student at IIE Varsity College. I am currently conducting research under the supervision of Lisa Weideman about the challenges of integrating women in leadership positions in technology industry. I hope that this research will enhance our understanding of the main challenges faced by women towards their career advancement in technology industry.

I would like to invite you to participate in my study. In order to explain to you what your participation in my study will involve, I have formulated questions that I will try to fully answer so that you can make an informed decision about whether or not to participate. If you have any additional questions that you feel are not addressed or explained in this information sheet, please do not hesitate to ask me for more information. Once you have read and understood all the information contained in this sheet and are willing to participate, please complete and sign the consent form below. 


\section{What will I be doing if I participate in your study?}

I would like to invite you to participate in this research because this study will focus on women in technology industry, and in order to understand this issue, women are most suitable to participate in this study. If you decide to participate in this research, i would like to have an honest description of your work experience in the industry.

You can decide whether or not to participate in this research. If you decide to participate, you can choose to withdraw at any time or to decide not to answer particular interview questions.

\section{Are there any risks/ or discomforts involved in participating in this study?}

Whether or not you decide to participate in this research, there will be no negative impact on you. There are no direct risks or benefits to you if you participate in this study. You might, however, indirectly find that it is helpful to talk about your (insert what you are examining). If you find at any stage that you are not comfortable with the line of questioning, you may withdraw or refrain from participating.

\section{Do I have to participate in the study?}

- Your inclusion in this study is completely voluntary;

- If you do not wish to participate in this study, you have every right not to do so;

- Even if you agree to participate in this study, you may withdraw at any time without having to

provide an explanation for your decision.

\section{Will my identity be protected?}

I promise to protect your identity. I will not use your name in any research summaries to come out of this research and I will also make sure that any other details are disguised so that nobody will be able to identify you. I would like to ask your permission to record the interviews, but only my supervisor, I and possibly a professional transcriber (who will sign a confidentiality agreement) will have access to these recordings. Nobody else, including anybody at (insert The IIE brand's name), will have access to your interview information. I would like to use quotes when I discuss the findings of the research, but I will not use any recognizable information in these quotes that can be linked to you.

\section{What will happen to the information that participants provide?}

Once I have finished all interviews, I will write summaries to be included in my research 
report, which is a requirement to complete my Bachelor of commerce Honours degree in management.

You may ask me to send you a summary of the research if you are interested in the final outcome of the study.

\section{What happens if I have more questions about the study?}

Please feel free to contact me or my supervisor should you have any questions or concerns about this research, or if there is anything you need to know before you decide whether or not to participate.

You should not agree to participate unless you are completely comfortable with the procedures followed.

\section{My contact details are as follows:}

Dionisia Cidre

+27 740171865

Vazcidre77@gmail.com

The contact details of my supervisor are as follows:

Lisa Weideman

lweideman@varsitycollege.co.za 
International Journal of Innovation, Creativity and Change. www.ijicc.net

Volume 15, Issue 4, 2021

10. Annexure: Ethical Clearance Independent Institute of Education's Research and Postgraduate Studies Committee.

Your research proposal posed no significant ethical concerns and we hereby provide you with ethical clearance to proceed with your data collection.

There may be some aspects that you still need to address in your proposal. If this is the case, feedback will be provided to you in writing. You will need to address these aspects in consultation with your supervisor.

In the event of you deciding to change your research topic or methodology in any way, kindly consult your supervisor to ensure that all ethical considerations are adhered to and pose no risk to any participant or party involved. A revised ethical clearance letter will be issued in such instances.
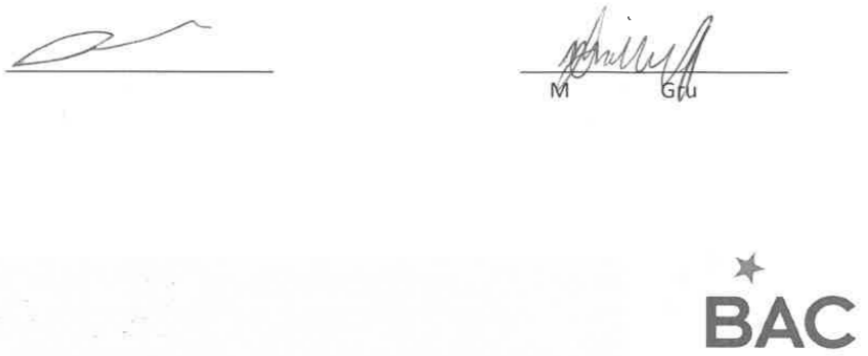
International Journal of Innovation, Creativity and Change. www.ijicc.net

Volume 15, Issue 4, 2021

11. Annexure A: Final Research Report Summary Document. Title: The challenges of integrating women in leadership positions in the technology industry



